\title{
The Use of Behavioral Modalities for Headache During Pregnancy and Breastfeeding
}

\author{
Nina Riggins ${ }^{1} \oplus \cdot$ Annika Ehrlich ${ }^{2}$
}

Accepted: 25 June 2021 / Published online: 19 October 2021

(c) The Author(s) 2021

\begin{abstract}
Purpose of Review Migraine is primary headache which commonly affects women of childbearing age. Migraine and other primary headache disorders are also common during pregnancy. Understanding which treatments are effective and can be safely given to patients with primary headache during pregnancy and lactation is essential in supporting these patients before, during, and after childbirth. Behavioral modalities have the potential to improve the health of both mother and baby, while empowering patients to make informed decisions in family planning and creating future treatment plans.

Recent Findings Research shows that behavioral therapies can be powerful tools to treat pain conditions with minimal side effects. Recent literature prioritizes behavioral therapies in preparation for pregnancy, during pregnancy, and during lactation due to the superior safety profile of such therapies. Digital resources for behavioral therapy are another well-received recent direction supported by growing evidence of both efficacy and safety. Popular with patients and headache specialists, digital behavioral therapy has taken various forms during the pandemic, such as telemedicine, online psychology support groups, and smartphone applications that patients can interact with on their own time.

Summary In summary, the purpose of this review is to equip providers with important information and updates on the use of behavioral modalities for the treatment of primary headache during pregnancy and lactation.
\end{abstract}

Keywords Headache $\cdot$ Migraine $\cdot$ Pregnancy $\cdot$ Lactation $\cdot$ Cognitive behavioral therapy $\cdot$ Meditation $\cdot$ Relaxation

\section{Introduction}

Migraine and other primary headache disorders (such as trigeminal autonomic cephalalgias) are common during pregnancy affecting $10-17 \%$ of pregnancies $[1 \bullet \bullet]$.

Recent research suggests that, despite the possible improvement of a majority of patients with migraine by the third trimester, one in five women avoided pregnancy because of migraine with concerns that migraine will get worse, affect the health of their child, or both $[1 \bullet \bullet, 2,3,4]$. It

This article is part of the Topical Collection on Psychological and Behavioral Aspects of Headache and Pain

Nina Riggins

nina.riggins7@gmail.com

1 UCSF Medical School, UCSF Headache Center, University of California, San Francisco, CA, USA

2 UCSF Headache Center, UCSF School of Nursing, University of California, San Francisco, CA, USA is also common for women undergoing headache treatment to express concern before pregnancy about having to stop such treatments that were effective because they are not approved safe during pregnancy. An example of such a situation is a woman who has improvement of migraine while using calcitonin gene-related peptide (CGRP) antibodies for migraine prevention and who is taken off this medication months prior to becoming pregnant due to lack of evidence that it is safe during pregnancy. The crucial question becomes, what are safe and effective treatments for migraine in preparation for pregnancy, during pregnancy and during lactation?

Stress and hormonal changes are known triggers for migraine attacks [5]. There is a dual challenge to give a woman the most effective treatment that is safe for both her and her baby. There is a realization that undertreatment of headache during pregnancy and lactation can lead to negative sequences for women and for familial relations, such as interfering with mother-child bonding [ $[\bullet \bullet]$.

Challenges with risks and benefits of medications, procedures, and devices make behavioral modalities an attractive 
option for management of headache during pregnancy and lactation, and in preparation for pregnancy. In this review, we identify potential behavioral interventions to consider before and during pregnancy and after childbirth.

Because literature on this subject is scarce, we used direct evidence-such as research discussing effects and side effects during pregnancy and lactation-and also indirect evidence-behavioral modalities we have and future directions of research in the general population of people living with primary headache.

Therefore, the goal of this review is to equip providers with important information and updates regarding the use of behavioral modalities for the safe and effective treatment of primary headache during pregnancy and lactation.

\section{Research Methods}

We consulted with a research librarian affiliated with our institution, who assisted with our PubMed search regarding any published articles with the following keywords/phrases:

(pregnancy[ti] OR pregnant[ti] OR lactation[ti]

OR lactating[ti] OR breast feeding[ti] OR

breastfeeding[ti] OR pregnancy[ot] OR pregnant[ot]

OR lactation[ot] OR lactating[ot] OR breast

feeding[ot] OR breastfeeding[ot] OR pregnancy[mh]

OR lactation [mh] OR breast feeding [mh) AND (pri-

mary headache OR "headache disorders, primary"

[mh] OR migraine OR cluster headache) AND (behav-

ioral therapy $O R$ exercise OR yoga OR meditation $O R$

mindfulness OR stress reduction)

With these specific search terms, 150 articles were found with no time limitations. We prioritized the most recent evidence (within the past 3 years) regarding behavioral therapies specifically for treatment of headache in pregnancy and breastfeeding and included 48 articles in this review.

\section{Disclosure of Possible Bias and Research Obstacles}

Before we begin the substantive portion of the review, we must disclose possible bias and research obstacles.

Psychiatric comorbidities such as depression and anxiety can be seen more frequently in patients with primary headache disorders $[6,7]$. Behavioral modalities, such as cognitive behavioral therapy (CBT), biofeedback, progressive muscle relaxation therapy (PMR), acupuncture, and physical therapy (PT) can be beneficial for psychiatric comorbidities, and also insomnia [8]. One of the by-products of such treatment could be that migraine and other primary headaches improve as comorbidities and sleep improve. Such results have the potential to bias findings. More studies are needed to show by which exact mechanisms patients are getting better with behavioral modalities and what can be addressed the best with certain treatments.

In terms of research, there are not enough randomized clinical trials to draw conclusions based on studies in patients who are preparing for pregnancy, pregnant, or breastfeeding, and many conclusions had to be done based on general population of patients with primary headache and retrospective reviews.

Lastly, relaxation, biofeedback, and cognitive behavioral therapy are evidence-based behavioral therapies for migraine $[8,9]$. Digital resources and motivational interviewing can help patients overcome barriers to start behavioral therapy, especially during the Covid-19 pandemic [10].

\section{Growing Evidence of the Effectiveness of Behavioral Modalities}

Behavioral modalities can help to empower patients as they learn to change body responses to pain and adapt their understanding of headache pain to a more proactive approach.

An informal survey of relevant literature and media clearly indicates that there is a growing body of evidence showing the important role of empowering patients with self-help tools and treatments for headache, including the use of a headache diary, trigger control, relaxation techniques, healthy foods and lifestyle, and regular exercise, all of which endeavor to give patients more control over their headache pain $[11,12 \bullet \bullet, 13]$.

Evidence accumulated over several years finds that people with primary headache disorders can achieve a 45 to $60 \%$ reduction in headache intensity and frequency with proper and regular use of biofeedback and relaxation techniques such as progressive muscle relaxation [14]. This evidence is supported by established EMG Biofeedback and the latest technology findings [14].

Technology has helped make significant improvements in understanding the mind-body connection. For example, in one study after 8 weekly CBT sessions, not only did headache frequency decrease, but structural and resting-state blood-oxygen-level-dependent contrast MRI scans showed changes in brain function and amygdala connectivity with brain regions responsible for the procession of pain, regulation of emotions, and cognitive function [15].

\section{Research on Headache During Pregnancy and Lactation}

Based on research, lifestyle modifications are a necessary first intervention that should be discussed in preparation for pregnancy, during pregnancy, and during lactation with every patient who has primary headache $[1 \bullet \bullet]$.

There is ample research indicating that women experience migraine more often than men. The female-to-male 
prevalence ratio of migraine is 3:1 [16]. Women experience a higher percentage of migraine during reproductive age $[17 \bullet]$. It is believed that estrogen can lower the threshold for cortical spreading depression [18].

In addition, there is a strong association between pregnancy and migraine, with studies showing $80 \%$ of women can experience migraine during pregnancy if they had it in the past $[17 \bullet, 19]$. Over one half of women with migraine experience recurrence of headaches within the first month after childbirth [17•, 20]. Although there is no direct evidence to suggest that breastfeeding can trigger migraine or worsen other primary headache, there is a reasonable expectation that many parents of newborns can have sleep deprivation which can trigger migraine. In this context, the lack of sleep is not due to insomnia and therefore any resulting headache may be associative.

Digital cognitive behavioral therapy is readily available for headache patients. In one proof-of-concept study, $34 \%$ of patients with chronic migraine who completed a digital cognitive behavioral course reverted from chronic migraine to episodic migraine [21]. In addition, $50 \%$ of the participants reported improvement in insomnia. The study provided additional evidence for the feasibility and acceptability of dCBTI in patients with chronic migraine and insomnia, suggesting the beneficial effects of treating both insomnia and migraine concurrently [21].

Some people may prefer in-person sessions while others may prefer smartphone-delivered therapy. The new era of headache management gives easier access and removes many of the traditional barriers to access behavioral therapy, including socioeconomic and logistical. For example, a study of 401 participants showed that patients with migraine preferred digital or in-person behavioral therapy to phone therapy [22].

\section{Planting the SEEDS of Successful Outcomes}

The SEEDS mnemonic stands for "Sleep, Exercise, Eat, Diary, and Stress". [11]. It has become a popular mantra among providers who care for patients living with migraine and other headache disorders. Studies show that relaxation training and biofeedback should be regularly used to assist headache prevention and help treat acute headache and migraine $[17 \bullet, 23]$.

Behavior therapy is not limited to the USA where behavioral modifications are commonly espoused in popular media. Reports of successful behavioral therapy intervention have emerged in medical literature sampled from regions around the world. To sharpen the focus, for behavioral therapy approaches we selected biofeedback, cognitive behavioral therapy, relaxation techniques, mindfulness-based therapy, and acceptance and commitment therapy. In a review from Italy published this year (2021), the author emphasized that behavioral modalities should specifically target pregnant women due to tolerability [20]. Similar to this review, these authors selected biofeedback, cognitive behavioral therapy, relaxation techniques, mindfulness-based therapy, and acceptance and commitment therapy for their review.

Research shows that mindfulness-based therapy improves migraine and tension headache and intervene in at least one

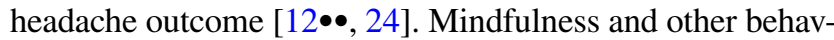
ioral modalities are becoming more popular while gaining more evidence of efficacy and tolerability [12••, 13, 25,26,27].

Several studies show that biofeedback is effective in the

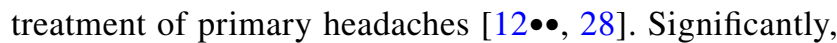
studies also show that behavioral therapy is not only effective when administered in conjunction with treatment using medications, but also effective on its own $[29,30 \bullet]$. One formal behavioral therapy technique called Acceptance and Commitment Therapy (ACT) uses several strategies together, incorporating mindfulness, engagement in action, and behavior modification [31,32,33].

\section{Proven Benefits of Exercise and Mindfulness}

Healthcare professionals and laypersons have long known that exercise is good for a person's physical well-being. Over the past several years, both groups have started to recognize the mental health benefits of exercise. Most recently, there is evidence emerging that exercise has proven physical and mental health benefits in the treatment of chronic pain such as migraine and headache. While we have understood the preventative benefits of exercise, recommending it as a form of treatment is a significant step in the evolution of pain medicine. Groundbreaking research in this area clearly indicates that regular, individualized exercise-based treatments are likely to result in improvements in pain and function, including for headache and migraine [34•, 35,36,37,38].

There is emerging evidence for the beneficial role of mindfulness, yoga, and tai chi in the treatment of migraine. Mindful breathing, yoga postures, and meditation can reduce stress. Mindfulness-based interventions (MBI) have potential as a non-pharmacological treatment for migraine, primarily through the development of flexible attention capacity across sensory, cognitive, and emotional experiences [27, $30 \bullet, 34 \bullet, 39,40]$.

In another study, researchers used a survey to look at outcomes of 12 weeks of yoga in females with migraine [41]. Here the researchers were interested in headache frequency, intensity, duration, and blood nitric oxide levels and functioning. Their results showed significant reduction in headache and better functioning without significant difference in the plasma levels of nitric oxide between those in yoga therapy and the control groups before and after the study.

Data indicates that yoga is a promising treatment in the management of chronic pain [42]. Researchers have worked 
on understanding how yoga helps chronic pain and migraine. Studies show that yoga decreases disability among people with pain, but it is not known exactly how. A validated conceptual model of how the experience of chronic pain is affected by yoga is being looked at [43], and the beneficial effects of yoga on migraine are being studied [44, 45].

Tai chi is a gentle meditative sequence of movements. It is an exercise targeted to improve health by changes in mental focus, breathing, coordination, and relaxation. There is research to show that during pregnancy women with migraine may benefit by practicing tai chi. In one study, tai chi practice was shown to help in the reduction of headache impact, improve perceptions of some aspects of physical health, and benefit mental health $[46,47]$.

\section{Conclusions}

Migraine is a chronic disabling neurologic condition that can be treated with a combination of both pharmacologic and complementary and integrative health options [48]. To quote one study: "Within a biopsychosocial approach, a multidisciplinary program for headache management should be planned. It should include not only conventional pharmacological therapies but also: patient education and support, lifestyle modification (diet, physical activity, lifestyle habits, stressful conditions, etc.), and complementary measures" $[12 \bullet \bullet]$.

Recent findings show that behavioral therapies can be powerful tools to treat pain conditions such as headache and migraine with minimal side effects. Due to the excellent safety profile of behavioral therapies, recent literature prioritizes behavioral therapies for women preparing to get pregnant, during pregnancy, and during lactation. An exciting and democratizing recent trend is digital resources for behavioral therapy, which are well received and have growing evidence for efficacy and safety. Digital behavioral therapy has greatly expanded during the Covid-19 pandemic, manifesting in different forms. Both the delivery and efficacy have been well-received by headache patients and providers. Telemedicine pain centers, online psychology support groups, and smartphone apps are ubiquitous thanks to their convenience.

Behavioral modalities may be an excellent first choice and also an option to augment other treatments for patients with headache during preparation for pregnancy, during pregnancy and lactation. Understanding which treatments are effective and can be safely offered during pregnancy and lactation to patients with primary headache is essential in supporting these patients. This has potential to improve the health of mother and baby, while giving patients the power to make informed decisions in family planning and creating lifelong treatment plans.
Lastly, there are few randomized clinical trials evaluating the efficacy and safety of behavioral modalities in patients who are pregnant and breastfeeding. Future research with emphasis on this population would be very beneficial.

Acknowledgements The authors greatly appreciate the following individuals for their contributions in helping us in the preparation for this paper: Vivian Nguyen, BA candidate (2022) UC Berkeley, UCSF Headache Center Volunteer. Evans Whitaker, MD, MLIS, Research Librarian with UCSF Health Sciences Library.

\section{Compliance with Ethical Standards}

Conflict of Interest Dr. Riggins declares serving as PI on an Electrocore study, PI on Eli Lilly study, Co-PI on a Theraspecs study, consultant for Gerson Lehman Group.

Ms. Ehrlich serves on speaker bureau for Lilly and Allergan pharmaceuticals, has served on advisory Boards for Impel Neuropharma and Currax Pharmaceuticals. She has consulted for Allergan and for Dieker Copple PLLC. She is the Co-PI on a Theraspecs study.

Human and Animal Rights and Informed Consent This article does not contain any studies with human or animal subjects performed by any of the authors.

Open Access This article is licensed under a Creative Commons Attribution 4.0 International License, which permits use, sharing, adaptation, distribution and reproduction in any medium or format, as long as you give appropriate credit to the original author(s) and the source, provide a link to the Creative Commons licence, and indicate if changes were made. The images or other third party material in this article are included in the article's Creative Commons licence, unless indicated otherwise in a credit line to the material. If material is not included in the article's Creative Commons licence and your intended use is not permitted by statutory regulation or exceeds the permitted use, you will need to obtain permission directly from the copyright holder. To view a copy of this licence, visit http://creativecommons.org/licenses/by/4.0/.

\section{References}

Papers of particular interest, published recently, are highlighted as follows and annotated:

- Of importance

$\bullet$ Of major importance

1.• Saldanha IJ, Cao W, Bhuma MR, Konnyu KJ, Adam GP, Mehta $\mathrm{S}$, et al. Management of primary headaches during pregnancy, postpartum, and breastfeeding: a systematic review. Headache: J Headache Pain. 2021;61:11-43. https://doi.org/10.1111/head. 14041. Article provides current systematic literature review of the different treatment modalities in management of primary headaches during pregnancy, postpartum, and breastfeeding.

2. Ishii R, Schwedt TJ, Kim SK, Dumkrieger G, Chong CD, Dodick DW. Effect of migraine on pregnancy planning: insights from the American Registry for Migraine Research. InMayo Clinic Proceedings 2020 (Vol. 95, No. 10, pp. 2079-2089). ISSN 00256196. https://doi.org/10.1016/j.mayocp.2020.06.053. 
3. Lampl C, Thomas H, Stovner LJ, et al. Interictal burden attributable to episodic headache: findings from the Eurolight project. J Headache Pain. 2016;17:9. https://doi.org/10.1186/ s10194-016-0599-8.

4. Buse DC, Fanning KM, Reed ML, Murray S, Dumas PK, Adams AM, et al. Life with migraine: effects on relationships, career, and finances from the Chronic Migraine Epidemiology and Outcomes (CaMEO) Study. Headache. 2019;59(8):128699. https://doi.org/10.1111/head.13613 Epub 2019 Aug 12. PMID: 31407321; PMCID: PMC6771487.

5. Pellegrino ABW, Davis-Martin RE, Houle TT, Turner DP, Smitherman TA. Perceived triggers of primary headache disorders: a meta-analysis. Cephalalgia. 2018;38(6):1188-98. https:// doi.org/10.1177/0333102417727535 (Epub 2017 Aug 20 PMID: 28825314).

6. Minen MT, Begasse De Dhaem O, Kroon Van Diest A, Powers S, Schwedt TJ, Lipton R, et al. Migraine and its psychiatric comorbidities. J Neurol Neurosurg Psychiatry. 2016;87(7):741-9.

7. Buse DC, Reed ML, Fanning KM, Bostic R, Dodick DW, Schwedt TJ, et al. Comorbid and co-occurring conditions in migraine and associated risk of increasing headache pain intensity and headache frequency: results of the migraine in America symptoms and treatment (MAST) study. J Headache Pain. 2020;21(1):23.

8. Pérez-Muñoz A, Buse DC, Andrasik F. Behavioral interventions for migraine. Neurol Clin. 2019;37(4):789-813.

9. Silberstein SD. Practice parameter: evidence-based guidelines for migraine headache (an evidence-based review): report of the Quality Standards Subcommittee of the American Academy of Neurology. Neurology. 2000;55(6):754-62.

10. Minen MT, Sahyoun G, Gopal A, Levitan V, Pirraglia E, Simon $\mathrm{NM}$, et al. A pilot randomized controlled trial to assess the impact of motivational interviewing on initiating behavioral therapy for migraine. Headache: J Headache Pain. 2020;60:44156. https://doi.org/10.1111/head.13738.

11. Robblee J, Starling AJ. SEEDS for success: lifestyle management in migraine. Cleve Clin J Med. 2019;86(11):741-9. https://doi. org/10.3949/ccjm.86a.19009 (PMID: 31710587).

12.• Grazzi L, Toppo C, D’Amico D, et al. Non-pharmacological approaches to headaches: non-invasive neuromodulation, nutraceuticals, and behavioral approaches. Int J Environ Res Public Health. 2021;18(4):1503. Published 2021 Feb 5. https://doi.org/ $10.3390 /$ ijerph 18041503. Article is an excellent overview of non-pharmacological treatment modalities that can be applicable to Headache treatment during pregnancy and lactation.

13. Raggi A, Grignani E, Leonardi M, Andrasik F, Sansone E, Grazzi L, et al. Behavioral approaches for primary headaches: recent advances. Headache. 2018;58(6):913-25. https://doi.org/ 10.1111/head.13337 Epub 2018 May 26 PMID: 29802634.

14. Holroyd K, Penzien D, Rains J, et al. Behavioral management of headaches. In: Silberstein S, Lipton R, Dodick D, editors., et al., Wolff's headache and other head pain. 8th ed. New York, NY: Oxford University Press; 2008. p. 721-46.

15. Nahman-Averbuch H, Schneider VJ, Chamberlin LA, Kroon Van Diest AM, Peugh JL, Lee GR, et al. Alterations in brain function after cognitive behavioral therapy for migraine in children and adolescents. Headache: J Headache Pain. 2020;60:1165-82. https://doi.org/10.1111/head.13814.

16. Burch R, Rizzoli P, Loder E. The prevalence and impact of migraine and severe headache in the United States: figures and trends from government health studies. Headache. 2018;58(4):496-505. https://doi.org/10.1111/head.13281 (Epub 2018 Mar 12 PMID: 29527677).

17. Burch R. Epidemiology and treatment of menstrual migraine and migraine during pregnancy and lactation: a narrative review. Headache: J Headache Pain. 2020;60:200-16. https://doi.org/10. 1111/head.13665. Review provides excellent points on management of Migraine during pregnancy and breastfeeding.

18. Eikermann-Haerter K, Baum MJ, Ferrari MD, van den Maagdenberg AM, Moskowitz MA, Ayata C. Androgenic suppression of spreading depression in familial hemiplegic migraine type 1 mutant mice. Ann Neurol. 2009;66(4):564-8. https://doi.org/10.1002/ana.21779.

19. Frederick IO, Qiu C, Enquobahrie DA, et al. Lifetime prevalence and correlates of migraine among women in a pacific northwest pregnancy cohort study. Headache. 2014;54(4):675-85. https:// doi.org/10.1111/head.12206.

20. Sances G, Granella F, Nappi RE, Fignon A, Ghiotto N, Polatti $\mathrm{F}$, et al. Course of migraine during pregnancy and postpartum: a prospective study. Cephalalgia. 2003;23(3):197-205. https:// doi.org/10.1046/j.1468-2982.2003.00480.x PMID: 12662187.

21. Crawford MR, Luik AI, Espie CA, Taylor HL, Burgess HJ, Jones AL, et al. Rush University Sleep Research Team, Ong JC. Digital cognitive behavioral therapy for insomnia in women with chronic migraines. Headache: J Headache Pain. 2020;60: 902-15. https://doi.org/10.1111/head.13777.

22. Minen MT, Jalloh A, Begasse de Dhaem O, Seng EK. Behavioral therapy preferences in people with migraine. Headache: $\mathbf{J}$ Headache Pain. 2020;60:1093-102. https://doi.org/10.1111/head. 13790.

23. Millstine D, Chen CY, Bauer B. Complementary and integrative medicine in the management of headache. BMJ. 2017;16(357): j1805. https://doi.org/10.1136/bmj.j1805 (PMID: 28512119).

24. Cathcart S, Galatis N, Immink M, Proeve M, Petkov J. Brief mindfulness-based therapy for chronic tension-type headache: a randomized controlled pilot study. Behav Cogn Psychother. 2014;42(1):1-15. https://doi.org/10.1017/S1352465813000234 Epub 2013 Apr 3 PMID: 23552390.

25. Perlini C, Donisi V, Del Piccolo L. From research to clinical practice: a systematic review of the implementation of psychological interventions for chronic headache in adults. BMC Health Serv Res. 2020;20:459. https://doi.org/10.1186/ s12913-020-05172-y.

26. Sun-Edelstein C, Mauskop A. Alternative headache treatments: nutraceuticals, behavioral and physical treatments. Headache: J Headache Pain. 2011;51:469-83. https://doi.org/10.1111/j.15264610.2011.01846.x.

27. Wells RE, O'Connell N, Pierce CR, Estave P, Penzien DB, Loder $\mathrm{E}$, et al. Effectiveness of mindfulness meditation vs headache education for adults with migraine: a randomized clinical trial. JAMA Intern Med. 2021;181(3):317-28.

28. Rausa M, Palomba D, Cevoli S, Lazzerini L, Sancisi E, Cortelli $\mathrm{P}$, et al. Biofeedback in the prophylactic treatment of medication overuse headache: a pilot randomized controlled trial. J Headache Pain. 2016;17(1):1-8. https://doi.org/10.1186/s10194016-0679-9 Epub 2016 Sep 22. (PMID: 27655371; PMCID: PMC5031562).

29. Lee HJ, Lee JH, Cho EY, Kim SM, Yoon S. Efficacy of psychological treatment for headache disorder: a systematic review and meta-analysis. J Headache Pain. 2019;20(1):17. Published 2019 Feb 14. https://doi.org/10.1186/s10194-019-0965-4

30. Wells RE, Burch R, Paulsen RH, Wayne PM, Houle TT, Loder E. Meditation for migraines: a pilot randomized controlled trial. Headache. 2014;54(9):1484-95. https://doi.org/10.1111/head. 12420. Epub 2014 Jul 18. (PMID: 25041058). Publication of randomized controlled trial evaluating effects of 8-week standardized mindfulness course in people living with migraine.

31. Hayes SC, Luoma JB, Bond FW, Masuda A, Lillis J. Acceptance and commitment therapy: Model, processes and outcomes. Behav Res Ther. 2006;44:1-25. [CrossRef] 
32. Hughes LS, Clark J, Colclough JA, Dale E, McMillan D. Acceptance and commitment therapy (ACT) for chronic pain. Clin J Pain. 2017;33:552-68. [CrossRef]

33. Grazzi L, Bernstein C, Raggi A, Sansone E, Grignani E, Searl M, et al. ACT for migraine: Effect of acceptance and commitment therapy (ACT) for high-frequency episodic migraine without aura: Preliminary data of a phase-II, multicentric, randomized, open-label study. Neurol Sci. 2019;40:191-2. [CrossRef] [PubMed]

34. Wells RE, Seng EK, Edwards RR, Victorson DE, Pierce CR, Rosenberg L, et al. Mindfulness in migraine: a narrative review. Expert Rev Neurother. 2020;20(3):207-25. https://doi.org/10. 1080/14737175.2020.1715212. Review of potential mechanisms and efficacy of mindfulness in migraine treatment.

35. Borisovskaya A, Chmelik E, Karnik A. Exercise and Chronic Pain. Adv Exp Med Biol. 2020;1228:233-53. https://doi.org/ 10.1007/978-981-15-1792-1_16 (PMID: 32342462).

36. Carvalho GF, Schwarz A, Szikszay TM, Adamczyk WM, Bevilaqua-Grossi D, Luedtke K. Physical therapy and migraine: musculoskeletal and balance dysfunctions and their relevance for clinical practice. Braz J Phys Ther. 2020;24(4):306-17. https:// doi.org/10.1016/j.bjpt.2019.11.001.

37. Lemmens J, De Pauw J, Van Soom T, et al. The effect of aerobic exercise on the number of migraine days, duration and pain intensity in migraine: a systematic literature review and metaanalysis. J Headache Pain. 2019;20:16. https://doi.org/10.1186/ s10194-019-0961-8.

38. Barber M, Pace A. Exercise and migraine prevention: a review of the literature. Curr Pain Headache Rep. 2020;24(8):39. https:// doi.org/10.1007/s11916-020-00868-6 (PMID: 32529311).

39. Seng EK, Singer AB, Metts C, Grinberg AS, Patel ZS, Marzouk $\mathrm{M}$, et al. Does mindfulness-based cognitive therapy for migraine reduce migraine-related disability in people with episodic and chronic migraine? A phase $2 \mathrm{~b}$ pilot randomized clinical trial. Headache. 2019;59(9):1448-67. https://doi.org/10.1111/ head.13657 (Epub 2019 Sep 26. PMID: 31557329; PMCID: PMC6788949).

40. Day MA, Ward LC, Ehde DM, Thorn BE, Burns J, Barnier A, et al. A pilot randomized controlled trial comparing mindfulness meditation, cognitive therapy, and mindfulness-based cognitive therapy for chronic low back pain. Pain Medicine. 2019;20(11):2134-48. https://doi.org/10.1093/pm/pny273.
41. Boroujeni MZ, Marandi SM, Esfarjani F, Sattar M, Shaygannejad $\mathrm{V}$, Javanmard SH. Yoga intervention on blood NO in female migraineurs. Adv Biomed Res. 2015;31(4):259. https://doi. org/10.4103/2277-9175.172995(PMID:26918241;PMCID: PMC4746941).

42. Büssing A, Ostermann T, Lüdtke R, Michalsen A. Effects of yoga interventions on pain and pain-associated disability: a meta-analysis. J Pain. 2012;13(1):1-9. https://doi.org/10.1016/j. jpain.2011.10.001 (Epub 2011 Dec 16 PMID: 22178433).

43. Donaldson M. Resilient to pain: a model of how yoga may decrease interference among people experiencing chronic pain. Explore (NY). 2019;15(3):230-38. https://doi.org/10.1016/j. explore.2018.11.002 Epub 2018 Nov 14. (PMID: 30503690; PMCID: PMC6517077).

44. John PJ, Sharma N, Sharma CM, Kankane A. Effectiveness of yoga therapy in the treatment of migraine without aura: a randomized controlled trial. Headache. 2007;47(5):654-61. https:// doi.org/10.1111/j.1526-4610.2007.00789.x (PMID: 17501846).

45. Kisan R, Sujan MU, Adoor M, Rao R, Nalini A, Kutty BM, et al. Effect of yoga on migraine: a comprehensive study using clinical profile and cardiac autonomic functions. Int J Yoga. 2014;7(2):126-32. https://doi.org/10.4103/0973-6131.133891.

46. Wang C, Schmid CH, Fielding RA, Harvey WF, Reid KF, Price LL, et al. Effect of tai chi versus aerobic exercise for fibromyalgia: comparative effectiveness randomized controlled trial. BMJ. 2018;21(360). https://doi.org/10.1136/bmj.k851. (PMID: 29563100; PMCID: PMC5861462).

47. Abbott RB, Hui KK, Hays RD, Li MD, Pan T. A randomized controlled trial of tai chi for tension headaches. Evid Based Complement Alternat Med. 2007;4(1):107-13. https://doi.org/ 10.1093/ecam/nel050.

48. Patel PS, Minen MT. Complementary and integrative health treatments for migraine. J Neuroophthalmol. 2019;39(3):360-9. https://doi.org/10.1097/WNO.0000000000000841(PMID:3140 3967;PMCID:PMC7769000).

Publisher's Note Springer Nature remains neutral with regard to jurisdictional claims in published maps and institutional affiliations. 